\title{
ARTICLE Fatty Acid Profile of Muscles from Crossbred Angus-Simmental, Wagyu-Simmental, and Chinese Simmental Cattles
}

\section{OPEN ACCESS}

$\begin{array}{ll}\text { Received } & \text { January 17, } 2020 \\ \text { Revised } & \text { April 7, 2020 } \\ \text { Accepted } & \text { April 7, 2020 }\end{array}$

*Corresponding author: Zhao-Min Lei Faculty of Animal Science and Technology, Gansu Agricultural University, Gansu 730070, China

Tel: +86-931-7632459

Fax: +86-931-7632459

E-mail: zhaominlei19@163.com

\section{*ORCID}

Ting Liu

https://orcid.org/0000-0003-3760-8784

Jian-Ping Wu

https://orcid.org/0000-0001-9470-9210

Zhao-Min Lei

https://orcid.org/0000-0002-8144-6623

Ming Zhang

https://orcid.org/0000-0002-6661-1360

$\mathrm{Xu}$-Yin Gong

https://orcid.org/0000-0003-1618-0862

Shu-Ru Cheng

https://orcid.org/0000-0001-9107-3966

Yu Liang

https://orcid.org/0000-0002-3726-9295

Jian-Fu Wang

https://orcid.org/0000-0003-0821-0849

\author{
Ting Liu ${ }^{1}$, Jian-Ping $\mathrm{Wu}^{1,2}$, Zhao-Min Lei ${ }^{{ }^{*}}$, Ming Zhang ${ }^{1}$, Xu-Yin Gong ${ }^{2}$, \\ Shu-Ru Cheng ${ }^{1}$, Yu Liang ${ }^{3}$, and Jian-Fu Wang ${ }^{1}$ \\ ${ }^{1}$ Faculty of Animal Science and Technology, Gansu Agricultural University, Gansu \\ 730070, China \\ ${ }^{2}$ Gansu Academy of Agricultural Sciences, No. 1 Agricultural Academy Village \\ Anning, Gansu 730070, China \\ ${ }^{3}$ Department of Civil Engineering, College of Technology and Engineering, Lanzhou \\ University of Technology, Gansu 730070, China
}

\begin{abstract}
This study assessed breed differences in fatty acid composition and meat quality of Longissimus thoracis et lumborum (LTL) and semitendinosus (SE) of Angus $\times$ Chinese Simmental (AS), Wagyu $\times$ Chinese Simmental (WS), and Chinese Simmental (CS). CS ( $n=9)$, AS ( $=9)$ and WS (n=9) were randomly selected from a herd of 80 bulls which were fed and managed under similar conditions. Fatty acid profile and meat quality parameters were analyzed in duplicate. Significant breed difference was observed in fatty acid and meat quality profiles. AS exhibited significantly $(\mathrm{p}<0.05)$ lower $\mathrm{C} 16: 0$ and higher $\mathrm{C} 18: 1 \mathrm{n} 9 \mathrm{c}$ compared with CS. AS breed also had a tendency $(\mathrm{p}<0.10)$ to lower total saturated fatty acid (SFA), improve C18:3n3 and total unsaturated fatty acid (UFA) compared with CS. Crossbreed of AS and WS had significantly $(\mathrm{p}<0.05)$ improved the lightness, redness, and yellowness of muscles, and lowered cooking loss, pressing loss, and shear force compared with CS. These results indicated that fatty acid composition and meat quality generally differed among breeds, although the differences were not always similar in different tissues. Fatty acid composition, meat color, water holding capacity, and tenderness favored AS over CS. Thus, Angus cattle might be used to improve fatty acid and meat quality profiles of CS, and AS might contain better nutritive value, organoleptic properties, and flavor, and could be potentially developed as an ideal commercial crossbreed.
\end{abstract}

Keywords Angus, Chinese Simmental, Wagyu, crossbreed, fatty acid, meat quality

\section{Introduction}

In recent year, significant changes have taken place with respect to beef consumption in China. In 1996, the per capita consumption of beef was $2.82 \mathrm{~kg}$, which increased to $5.33 \mathrm{~kg}$ in 2014. The emphases on healthy life style and dietary habit of consumers

(C) Korean Society for Food Science of Animal Resources. This is an open access article distributed under the terms of the Creative Commons Attribution Non-Commercial License (http://creativecommons.org/licences/by-nc/3.0) which permits unrestricted non-commercial use, distribution, and reproduction in any medium, provided the original work is properly cited. 
have increased the demand for more flavorful and healthier meat (Resurreccion, 2004).

Beef fatty acid composition has received increasing attention due to their correlation for nutritional value, meat quality, palatability, and associated roles in human health (Wood et al., 2008). It has been proven in previous studies that eating quality, sensory properties, meat color, and shelf life are affected by the variety and amount of fatty acids in beef muscles (Calkins and Hodgen, 2007; Wood et al., 2004). For example, oleic acid (C18:1n-9) has positive correlation with beef flavour, while the ratio of monounsaturated to saturated fatty acids (MUFA:SFA) affects the taste and texture of beef (Garmyn et al., 2011).

Both non-genetic (feedstuff, fatness and age) and genetic (breed, sex and genotype) factors affect the fatty acid profile of meat (De Smet et al., 2004; Malau-Aduli et al., 2000). Breed is among the factors with a major influence on the fatty acid profile and meat quality of beef (Nuernberg et al., 2005). Breed differences in fatty acid compositions have been reported in the intramuscular fat of Angus, Hereford and their crossbreed (Papaleo Mazzucco et al., 2016), subcutaneous and intramuscular fat of Wagyu and Aberdeen Angus steers (May et al., 1993) intramuscular triacyglycerol and polar lipids of Simmental and Aberdeen Angus steers (Itoh et al., 1999), and intramuscular fat of Charolais, Hereford, Aberdeen Angus, and Simmental bulls (Bures et al., 2006). Therefore, it is likely that selecting genetically superior cattle can improve the contents of beneficial fatty acids and meat quality.

Currently, Chinese Simmental (CS), with its larger body size, fast growth and low intramuscular fat content features, is one of the most abundant breeds in western China. Angus and Wagyu beefs are the two most well-known breeds which are both known for their superior marbled appearance together with excellent favour, tenderness and meat color (Maltin et al., 2007). The present study aimed to determine breed differences in fatty acid profile and meat quality of Longissimus thoracis et lumborum (LTL) and semitendinosus (SE) muscles of Angus $\times$ Chinese Simmental (AS) $F_{1}$ bulls, Wagyu $\times$ Chinese Simmental (WS) $F_{1}$ bulls, and Chinese Simmental (CS). We hypothesized that the composition of fatty acids and the quality of meat in CS could be improved by crossbreeding with Angus or Wagyu.

\section{Material and Methods}

\section{Animal and harvest}

This study was approved by Animal Care and Use Committee of Gansu Agricultural University (Approved No. 2012-2159). All animal procedures were consistent with the Regulations for the Administration of Affairs Concerning Experimental Animals (The State Science and Technology Commission of China, 1988). Animals were harvested in conformity with the national standards of humane food animal harvesting and processing. CS bulls (CS, n=9), Angus (male) $\times$ CS (female) $F_{1}$ bulls (AS, n=9) and Wagyu (male) $\times$ CS (female) $F_{1}$ bulls (WS, n=9) were randomly selected from a herd of 80 bulls for a $180 \mathrm{~d}$ feeding trial after $14 \mathrm{~d}$ of conditioning period. All animals were fed and managed under similar conditions at JinChang. Animals at different growth periods were fed according to NRC requirements for the class and weight of the animals (Table 1). Both AS and WS were bred by artificial insemination with Angus and Wagyu sperm from American bulls. AS bulls were sired by 5 Angus bulls (Frozen semen numbers 014AN00365, 7AN00437, 14AN00513, 7AN00358, 7AN00437), and WS bulls were sired by 5 Wagyu bulls (Frozen semen numbers KSNJHN12050400, KSNJHN120416008, KSNJHN120409008, KSNJHN120423008, KSNJHN120410008). CS bulls were chosen from the progeny from 100 heads CS sire. At December $23^{\text {th }}, 2018$, all animals were transported to a commercial facility $97 \mathrm{~km}$ from the research center in Wuwei, and slaughtered after 0 min lairage time. Carcasses were chilled at $4^{\circ} \mathrm{C}$ for $72 \mathrm{~h}$. After aging, LTL and SE muscles were obtained from the left side of each animal carcass, individually vacuum packed, identified by animal number, and frozen at $-20^{\circ} \mathrm{C}$ until the time at which analyses were performed. All samples were analyzed in duplicate. 
Table 1. Feedlot rations for all breeds

\begin{tabular}{|c|c|c|c|c|c|c|c|}
\hline \multirow{2}{*}{ Feedstuff $(\%)$} & \multicolumn{7}{|c|}{ Stage weight $(\mathrm{kg})$} \\
\hline & $270-315$ & $315-360$ & $360-405$ & $405-450$ & $450-495$ & $496-540$ & $540-585$ \\
\hline Corn & 53.71 & 74.28 & 78.75 & 81.38 & 84.49 & 86.64 & 75.47 \\
\hline Flax & 30.34 & 19.27 & 14.66 & 10.29 & 7.71 & 5.48 & 12.14 \\
\hline Mountain flour & 1.15 & 0.76 & 0.61 & 0.45 & 0.35 & 0.3 & 0.47 \\
\hline Salt & 4.19 & - & - & - & - & - & - \\
\hline Calcium hydrophosphate & - & - & 0.09 & 0.16 & 0.2 & 0.2 & - \\
\hline Bicarb & 2.23 & - & - & 1.42 & 1.45 & 1.48 & 2.38 \\
\hline Premix $^{1)}$ & 8.91 & 5.69 & 5.89 & 5.68 & 5.81 & 5.9 & 9.54 \\
\hline Total & 100 & 100 & 100 & 100 & 100 & 100 & 100 \\
\hline \multicolumn{8}{|l|}{ Nutritional standard } \\
\hline $\operatorname{ADG}(\mathrm{kg} / \mathrm{d})$ & 1.125 & 1.35 & 1.35 & 1.35 & 1.35 & 1.35 & 1.125 \\
\hline $\mathrm{CP}(\% \mathrm{DM})$ & 11.6 & 12.29 & 11.34 & 10.71 & 10.08 & 9.66 & 9.59 \\
\hline TDN (\% DM) & 70 & 76.98 & 77 & 76.85 & 76.86 & 76.87 & 72.3 \\
\hline NEm (Mcal/100 kg) & 166.81 & 186.67 & 186.67 & 186.67 & 186.67 & 186.67 & 172.67 \\
\hline NEg (Mcal/100 kg) & 108.87 & 134.77 & 124.76 & 125.11 & 125.09 & 125.08 & 113.09 \\
\hline $\mathrm{Ca}(\% \mathrm{DM})$ & 0.53 & 0.49 & 0.44 & 0.39 & 0.35 & 0.32 & 0.29 \\
\hline $\mathrm{P}(\% \mathrm{DM})$ & 0.27 & 0.25 & 0.24 & 0.23 & 0.22 & 0.21 & 0.21 \\
\hline DMI (kg/d) & 6.75 & 7.425 & 8.19 & 8.955 & 9.675 & 10.395 & 10.62 \\
\hline
\end{tabular}

1) Vitamin-mineral premix: A, D3, E, Mn, Zn, Fe, Cu, Se, I, Co.

ADG, average daily gain; CP, crude protein; TDN, total digestible nutrient; NEm, net energy for maintainance; NEg, net energy for gain; Ca, calcium; P, phosphorus; DMI, dry matter intake.

\section{Fatty acid analysis}

Analysis of fatty acid composition in muscles was conducted following the previously published protocol with some modification (O'Fallon et al., 2007). Samples were uniformly distributed by grinding in liquid nitrogen. One gram of each sample was placed into a $16 \times 125 \mathrm{~mm}$ screw-cap Pyrex culture tube, added with $5.3 \mathrm{~mL}$ of $\mathrm{MeOH}$, and $0.7 \mathrm{~mL}$ of $10 \mathrm{~N} \mathrm{KOH}$ in water. Then, the tube was incubated in a water bath at $55^{\circ} \mathrm{C}$ for $2 \mathrm{~h}$ with vigorous shaking for $10 \mathrm{~s}$ every 20 min to promote proper permeation, dissolution, and hydrolysis. After incubation, the samples were cooled to below room temperature in a cold water bath. Then, $\mathrm{H}_{2} \mathrm{SO}_{4}(24 \mathrm{~N}, 0.58 \mathrm{~mL})$ in water was added, and the tubes were mixed by inversion. Once the precipitate of $\mathrm{K}_{2} \mathrm{SO}_{4}$ was present, the samples were incubated again in a water bath at $55^{\circ} \mathrm{C}$ for $2 \mathrm{~h}$ with hand-shaking for $10 \mathrm{~s}$ every $20 \mathrm{~min}$. After fatty acid methyl esters (FAME) synthesized, the samples were cooled again in a cold water bath. Then, samples were added with $3 \mathrm{~mL}$ of hexane, and the tubes were vortexed on a multitube vortex for 5 min followed by 5 min centrifugalization in a tabletop centrifuge. The hexane layer containing the FAME was collected and placed into a gas chromatography (GC) vial. The vial was capped and placed at $-20^{\circ} \mathrm{C}$ until $\mathrm{GC}$ analysis. GC (model $6890 \mathrm{~N}$, Aglient Technology, Wilmington, DE, USA) was used to separate and quantify the derivatized methyl ester of fatty acids. A fusedsilica column (SP-2560; Sigma-Aldrich, St. Louis, MO, USA), with $100 \mathrm{~m} \times 0.25 \mathrm{~mm} \times 0.2 \mu \mathrm{m}$ film thickness, was applied for the chromatographic separations. Carrier gas was nitrogen, with a split ratio of 100:1 and a column flow rate of $1 \mathrm{~mL} / \mathrm{min}$. The injector temperature was set at $260^{\circ} \mathrm{C}$. The temperature of the gas chromatograph column oven was initially programmed at $140^{\circ} \mathrm{C}$ for $4 \mathrm{~min}$ and then increased at a rate of $4^{\circ} \mathrm{C} / \mathrm{min}$ from $140^{\circ} \mathrm{C}$ to $230^{\circ} \mathrm{C}, 2{ }^{\circ} \mathrm{C} / \mathrm{min}$ from $230^{\circ} \mathrm{C}$ to $240^{\circ} \mathrm{C}$ and then 
maintained at $240^{\circ} \mathrm{C}$ for $10 \mathrm{~min}$. Thirty-seven FAME preparations (Supelco 37 Component FAME mix standard, SigmaAldrich) were injected respectively to relate the peaks to known FAMEs. The concentrations of each fatty acid from areas under the peaks, which were those adjacent to FAME in the standard mixture, were calculated using the retention times. The fatty acid concentration was expressed as the percentage of an individual fatty acid in the total fatty acid composition.

\section{Meat quality evaluation}

The $\mathrm{pH}$ values were measured directly in LTL muscle (at the $3^{\text {rd }}$ and $4^{\text {th }}$ reciprocal thoracic vertebrae) and in SE muscle (at a designated position) using a portable pH Meter HI98103 (Beijing Taiyasaifu, Beijing, China). The pH values given in the table were the averages of three measurements of each carcass. The meat color was assessed using a Minolta colorimeter (Chroma Meter CR-400, Minolta Camera, Osaka, Japan) to determine color coordinate values for L* (lightness), a* (redness), and $b^{*}$ (yellowness) following procedures of the Commission International de l'Eclairage (CIE). Reading of each of the $\mathrm{L}^{*}$, $\mathrm{a}^{*}$, and $\mathrm{b}^{*}$ values were taken at 3 spots on the surface, and each spot was repeated 4 times per $15 \mathrm{~cm}^{2}$. The values were averaged to obtain a representative reading of the surface color.

Meat samples with $2.5 \mathrm{~cm}$ thick of similar geometry were applied for determination of retort cooking lost. Samples were weighed, wrapped in a heat-resistant vacuum bag, and then cooked in a constant temperature water bath of $80^{\circ} \mathrm{C}$ to a final internal temperature of $70^{\circ} \mathrm{C}$. Internal temperature was monitored with a thermometer (with diameter of $0.5 \mathrm{~cm}$ ) inserted into the geometric center of the samples. At the final temperature, each sample was cooled in room temperature to $20^{\circ} \mathrm{C}$, dried with filter paper, and weighed. Raw and final sample weights were used to determine retort cooking loss.

Approximately $30 \mathrm{~g}$ of steak with similar geometry were weighed, and placed into a steamer of $100^{\circ} \mathrm{C}$ for $30 \mathrm{~min}$. Then, samples were cooled to room temperature, and weighed again. The difference between raw and heated weights was recorded as moist cooking lost and expressed as a proportion of the raw weight.

Raw samples of $1.0 \mathrm{~cm}$ thick were used for the determination of pressing lost. Samples were weighed to $0.001 \mathrm{~g}$, wrapped with gauze, and then sandwiched between 18 layers of filter paper with good water absorption, top to bottom. A weight of 35 $\mathrm{kg}$ was applied for $5 \mathrm{~min}$ and weight was recorded immediately after press. The difference between initial weight and post pressing weights was recorded as pressing lost and expressed as a proportion of the initial weight.

Meat samples with a center temperature of $0^{\circ} \mathrm{C}-4^{\circ} \mathrm{C}$ were obtained, cooked in a constant temperature water bath of $80^{\circ} \mathrm{C}$ to an internal temperature of $70^{\circ} \mathrm{C}$. At the final temperature, samples were removed from the bath and cooled to an internal temperature of $0^{\circ} \mathrm{C}-4^{\circ} \mathrm{C}$. At least three $1.27 \mathrm{~cm}$ diameter cores were removed from each sample parallel to the muscle fiber orientation. A peak shear force was obtained for each core perpendicular to muscle fiber orientation with a TA-XT Plus Texture Analyzer (Stable Micro System, Godalming, UK) equipped with a Warner-Bratzler shear head, and the value reported for each sample was the average of at least three evaluated cores.

\section{Statistical analysis}

The effect of breeds and tissues on fatty acid composition was assessed using PROC MIXED (SAS, Cary, NC, USA). The linear model used was:

$$
Y i j k=\mu+S i+G j+S G i j+e k(i j)
$$

where: Yijk is the observed value of the kth animal in the ith breeds and $j$ th tissues, $\mu$ is the mean value common to all 
observations, $S i$ the fixed effects of the $i t h$ breeds, $G j$ the fixed effects of the $j t h$ tissues, $S G i j$ the fixed interaction between the $i t h$ breeds and $j$ th tissues, and $e k(i j)$ is the random deviation of the $k t h$ animal in the ith breeds and $j t h$ tissues. The differences among means from different breeds were determined using one-way analysis of variance (ANOVA). For all variables analyzed, a p-value of $<0.05$ or $<0.01$ was considered as statistically significance, while $0.05<\mathrm{p}<0.10$ was identified as a trend.

\section{Results and Discussion}

\section{Slaughter traits}

A summary of slaughter traits was given in Table 2. No significant difference was found in slaughter weight, body side length, heart girth, chest width, and cannon circumference among the three breeds. CS bulls showed significantly higher values $(\mathrm{p}<0.05)$ of height at withers compared with WS. Chest depth was significantly higher $(\mathrm{p}<0.05)$ in CS bulls than in AS bulls. Also, CS bulls had significantly larger $(\mathrm{p}<0.05)$ hind leg circumference $(\mathrm{p}<0.05)$ compared with AS and WS breeds. It was observed that the carcass traits of AS and WS crossbreeds were not superior to CS bulls. Compared with Wagyu and Angus, CS breed has larger birth weight, rapid growth rate, and later maturing characteristics (Bures et al., 2006). Thus, crossbreeding CS with Wagyu and Angus might not lead to significant crossbreeding effect in carcass traits (Papaleo Mazzucco et al., 2016).

\section{Fatty acid composition}

The intramuscular SFA composition of the LTL and SE muscles in the three breeds was presented in Table 3. Total SFA took up approximately 50\% of all fatty acids in AS, WS, and CS breeds, with palmitic acid (C16:0), stearic acid (C18:0), and myristic acid (C14:0) together dominantly comprised more than 90\% of total SFA. Similar profiles were also presented in other literatures investigating Wagyu (Kazala et al., 1999; Mir et al., 2000), Angus (Purchas et al., 2005), Yak (Zhang et al., 2009), and other crossbred beefs (Coleman et al., 2016).

Table 2. Least squares means and standard errors for slaughter traits of Angus $\times$ CS, Wagyu $\times$ Chinese, and CS in longissimus dorsi and semitendinosus muscles

\begin{tabular}{lccc}
\hline Slaughter traits & AS & WS & CS \\
\hline Slaughter weight $(\mathrm{kg})$ & $602.44 \pm 59.95$ & $600.00 \pm 76.11$ & $586.22 \pm 44.38$ \\
Height at withers $(\mathrm{cm})$ & $129.06 \pm 4.32^{\mathrm{ab}}$ & $125.44 \pm 4.10^{\mathrm{b}}$ & $129.44 \pm 3.47^{\mathrm{a}}$ \\
Body side length $(\mathrm{cm})$ & $153.67 \pm 8.31$ & $151.28 \pm 8.05$ & $148.44 \pm 6.84$ \\
Heart girth $(\mathrm{cm})$ & $206.33 \pm 8.90$ & $204.33 \pm 8.90$ & $209.67 \pm 7.52$ \\
Chest depth $(\mathrm{cm})$ & $69.11 \pm 2.84^{\mathrm{b}}$ & $69.56 \pm 3.64^{\mathrm{ab}}$ & $72.67 \pm 3.35^{\mathrm{a}}$ \\
Chest width $(\mathrm{cm})$ & $50.94 \pm 2.38$ & $53.44 \pm 4.13$ & $54.33 \pm 5.87$ \\
Hind leg circumference $(\mathrm{cm})$ & $53.89 \pm 2.57^{\mathrm{b}}$ & $56.11 \pm 4.70^{\mathrm{b}}$ & $62.11 \pm 2.57^{\mathrm{a}}$ \\
Cannon circumference $(\mathrm{cm})$ & $20.60 \pm 1.42$ & $20.78 \pm 1.63$ & $20.39 \pm 1.36$ \\
\hline
\end{tabular}

a,b Values in the same line with different capital letter superscripts mean samples have significant difference. The same as below. ${ }^{*} \mathrm{p}<0.1 ;{ }^{* *} \mathrm{p}<0.05 ;{ }^{* * *} \mathrm{p}<0.01$.

AS, Angus $\times$ Chinese Simmental; WS, Wagyu $\times$ Chinese; CS, Chinese Simmental; LTL, longissimus thoracis et lumborum; SE, semitendinosus muscles. 
Table 3. Least squares means and standard errors for saturated fatty acids compositions of Angus $\times$ CS, Wagyu $\times$ Chinese, and CS in longissimus dorsi and semitendinosus muscles

\begin{tabular}{|c|c|c|c|c|c|}
\hline Saturated fatty acids & Tissue & AS & WS & $\mathrm{CS}$ & p-values \\
\hline \multirow[t]{2}{*}{$\mathrm{C} 4: 0$} & LTL & $0.09 \pm 0.02$ & $0.06 \pm 0.03$ & $0.10 \pm 0.25$ & \\
\hline & SE & $0.05 \pm 0.02$ & $0.06 \pm 0.03$ & $0.09 \pm 0.03$ & \\
\hline \multirow[t]{2}{*}{ C6:0 } & LTL & $0.04 \pm 0.10^{\mathrm{b}}$ & $0.02 \pm 0.12^{\mathrm{b}}$ & $0.33 \pm 0.11^{\mathrm{a}}$ & * \\
\hline & SE & $0.09 \pm 0.10$ & $0.06 \pm 0.12$ & $0.00 \pm 0.00$ & \\
\hline \multirow[t]{2}{*}{$\mathrm{C} 8: 0$} & LTL & $0.02 \pm 0.03$ & $0.05 \pm 0.04$ & $0.09 \pm 0.04$ & \\
\hline & SE & $0.09 \pm 0.03$ & $0.07 \pm 0.04$ & $0.07 \pm 0.04$ & \\
\hline \multirow[t]{2}{*}{$\mathrm{C} 10: 0$} & LTL & $0.06 \pm 0.02$ & $0.05 \pm 0.03$ & $0.10 \pm 0.03$ & \\
\hline & SE & $0.13 \pm 0.02$ & $0.07 \pm 0.03$ & $0.10 \pm 0.03$ & \\
\hline \multirow[t]{2}{*}{ C11:0 } & LTL & $0.04 \pm 0.01^{\mathrm{a}}$ & $0.03 \pm 0.01^{\mathrm{ab}}$ & $0.01 \pm 0.01^{\mathrm{b}}$ & $* *$ \\
\hline & SE & $0.01 \pm 0.01$ & $0.02 \pm 0.01$ & $0.01 \pm 0.01$ & \\
\hline \multirow[t]{2}{*}{$\mathrm{C} 12: 0$} & LTL & $0.19 \pm 0.06^{\mathrm{b}}$ & $0.34 \pm 0.07^{\mathrm{a}}$ & $0.23 \pm 0.06^{\mathrm{ab}}$ & * \\
\hline & SE & $0.10 \pm 0.06$ & $0.09 \pm 0.07$ & $0.12 \pm 0.07$ & \\
\hline \multirow[t]{2}{*}{$\mathrm{C} 13: 0$} & LTL & $0.31 \pm 0.14$ & $0.13 \pm 0.17$ & $0.23 \pm 0.16$ & \\
\hline & $\mathrm{SE}$ & $0.83 \pm 0.14^{\mathrm{a}}$ & $0.44 \pm 0.18^{\mathrm{b}}$ & $0.65 \pm 0.17^{\mathrm{ab}}$ & $*$ \\
\hline \multirow[t]{2}{*}{$\mathrm{C} 14: 0$} & LTL & $1.41 \pm 0.27^{\mathrm{b}}$ & $1.54 \pm 0.32^{\mathrm{ab}}$ & $2.17 \pm 0.30^{\mathrm{a}}$ & $*$ \\
\hline & SE & $1.74 \pm 0.27$ & $1.56 \pm 0.35$ & $1.91 \pm 0.32$ & \\
\hline \multirow[t]{2}{*}{$\mathrm{C} 15: 0$} & LTL & $0.43 \pm 0.07^{\mathrm{ab}}$ & $0.55 \pm 0.08^{\mathrm{a}}$ & $0.33 \pm 0.08^{\mathrm{b}}$ & $*$ \\
\hline & SE & $0.50 \pm 0.07$ & $0.45 \pm 0.09$ & $0.55 \pm 0.08$ & \\
\hline \multirow[t]{2}{*}{$\mathrm{C} 16: 0$} & LTL & $26.56 \pm 0.81$ & $26.66 \pm 0.97$ & $27.38 \pm 0.91$ & \\
\hline & SE & $23.66 \pm 0.81^{\mathrm{b}}$ & $25.53 \pm 1.05^{\mathrm{ab}}$ & $26.80 \pm 0.97^{\mathrm{a}}$ & $* *$ \\
\hline \multirow[t]{2}{*}{$\mathrm{C} 17: 0$} & LTL & $0.72 \pm 0.24^{\mathrm{b}}$ & $1.64 \pm 0.29^{\mathrm{a}}$ & $0.97 \pm 0.27^{\mathrm{ab}}$ & $* *$ \\
\hline & SE & $1.21 \pm 0.24$ & $1.26 \pm 0.31$ & $1.27 \pm 0.28$ & \\
\hline \multirow[t]{2}{*}{ C18:0 } & LTL & $20.41 \pm 1.05$ & $21.33 \pm 1.26$ & $21.71 \pm 1.18$ & \\
\hline & SE & $0.00 \pm 0.00$ & $0.00 \pm 0.00$ & $0.00 \pm 0.00$ & \\
\hline \multirow[t]{2}{*}{$\mathrm{C} 20: 0$} & LTL & $0.29 \pm 0.76$ & $0.27 \pm 0.91$ & $1.96 \pm 0.85$ & \\
\hline & $\mathrm{SE}$ & $1.33 \pm 0.76$ & $0.28 \pm 0.96$ & $0.00 \pm 0.00$ & \\
\hline \multirow[t]{2}{*}{$\mathrm{C} 21: 0$} & LTL & $0.18 \pm 0.07$ & $0.20 \pm 0.08$ & $0.23 \pm 0.08$ & \\
\hline & SE & $0.36 \pm 0.07$ & $0.33 \pm 0.09$ & $0.22 \pm 0.08$ & \\
\hline \multirow[t]{2}{*}{$\mathrm{C} 22: 0$} & LTL & $0.57 \pm 0.11$ & $0.44 \pm 0.14$ & $0.40 \pm 0.13$ & \\
\hline & SE & $0.30 \pm 0.11$ & $0.31 \pm 0.14$ & $0.37 \pm 0.14$ & \\
\hline \multirow[t]{2}{*}{$\mathrm{C} 23: 0$} & LTL & $0.81 \pm 0.40$ & $1.04 \pm 0.48$ & $0.49 \pm 0.45$ & \\
\hline & SE & $1.72 \pm 0.40$ & $1.69 \pm 0.52$ & $1.81 \pm 0.48$ & \\
\hline \multirow[t]{2}{*}{$\mathrm{C} 24: 0$} & LTL & $0.13 \pm 0.07^{\mathrm{ab}}$ & $0.40 \pm 0.09^{\mathrm{a}}$ & $0.07 \pm 0.08^{\mathrm{b}}$ & $* * *$ \\
\hline & SE & $0.26 \pm 0.07$ & $0.17 \pm 0.09$ & $0.25 \pm 0.09$ & \\
\hline \multirow[t]{2}{*}{ SFA } & LTL & $52.26 \pm 1.63^{b}$ & $54.77 \pm 1.95^{\mathrm{ab}}$ & $56.81 \pm 1.83^{\mathrm{a}}$ & * \\
\hline & SE & $49.18 \pm 1.63$ & $49.31 \pm 2.09$ & $52.95 \pm 1.94$ & \\
\hline
\end{tabular}

a,b Values in the same line with different capital letter superscripts mean samples have significant difference. The same as below.

${ }^{*} \mathrm{p}<0.1 ;{ }^{* *} \mathrm{p}<0.05 ;{ }^{* * *} \mathrm{p}<0.01$.

AS, Angus $\times$ Chinese Simmental; WS, Wagyu $\times$ Chinese; CS, Chinese Simmental; LTL, longissimus thoracis et lumborum; SE, semitendinosus muscles; SFA, saturated fatty acid. 
Breed difference was expressed in several fatty acids. C16:0 was significantly higher $(\mathrm{p}<0.05)$ in CS compared with AS breed in SE muscle, while C14:0 tended $(\mathrm{p}<0.1)$ to be higher in CS than in AS in LTL muscle. It is generally accepted that some SFA that are commonly found in meat, especially C16:0 and C14:0, raise the total cholesterol and low-density lipoprotein, and are thus risk factors in coronary heart disease (Erkkila et al., 2008; Webb and O'neill, 2008). Thus, AS breed, with lower proportion of $\mathrm{C} 16: 0$ and C14:0, might be more beneficial to human health. WS was found to have significantly higher $(\mathrm{p}<0.05)$ heptadecanoic acid $(\mathrm{C} 17: 0)$ compared with AS and higher $(\mathrm{p}<0.01)$ lignoceric acid $(\mathrm{C} 24: 0)$ compared with CS in LTL muscle. In addition, AS tended to have lower $(\mathrm{p}<0.1)$ caproic acid $(\mathrm{C} 6: 0)$ than $\mathrm{CS}$, lower $(\mathrm{p}<0.1)$ lauric acid $(\mathrm{C} 12: 0)$ than WS, and lower $(\mathrm{p}<0.1)$ total SFA than CS in LTL muscle. SFA is recognized as a critical predisposing factor in the development of cardiovascular diseases, and is implicated in cancers, obesity, diabetes and other health problems (Briggs et al., 2017; Pighin et al., 2016). Therefore, dietary recommendation promote foods that are low in saturated fat. Taken together, crossbreed of Angus (male) $\times$ Simmental (female) might have a preferable SFA profile that is more satisfied for the need of modern consumers than Wagyu (male) $\times$ Simmental (female) and Simmental (female), with significant lower C16:0 and C17:0, and a tendency to lower C6:0, C12:0, C14:0, and total SFA content.

The intramuscular unsaturated fatty acid (UFA) composition of the LTL and SE muscles in the three breeds was presented in Table 4. Total UFA ranged from $46.03 \%$ to $50.50 \%$ in LTL muscle, and from $50.24 \%$ to $53.35 \%$ in SE muscle. MUFA comprised the largest proportion of UFA, with oleic acid (C18:1n9c) being the most abundant. These results are in consistent with other studies on beef (Blanco et al., 2009; Domingo et al., 2015; Papaleo Mazzucco et al., 2016). Previous investigation

Table 4. Least squares means and standard errors for unsaturated fatty acids composition of Angus $\times$ CS, Wagyu $\times$ Chinese, and CS in longissimus dorsi and semitendinosus muscles

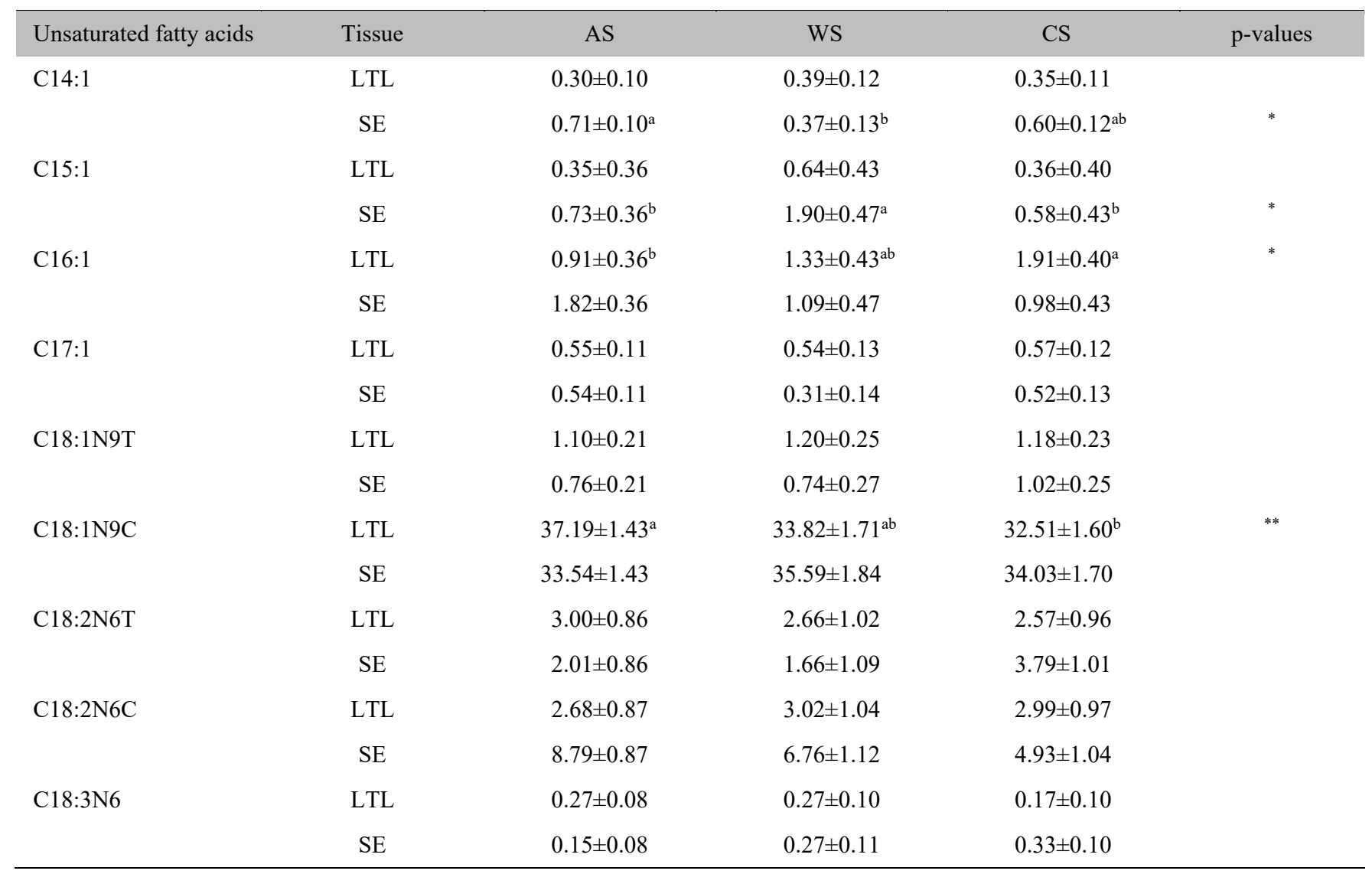


Table 4. Least squares means and standard errors for unsaturated fatty acids composition of Angus $\times$ CS, Wagyu $\times$ Chinese, and CS in longissimus dorsi and semitendinosus muscles (continued)

\begin{tabular}{|c|c|c|c|c|c|}
\hline Unsaturated fatty acids & Tissue & AS & WS & CS & p-values \\
\hline \multirow[t]{2}{*}{ C20:1 } & LTL & $0.16 \pm 0.06^{\mathrm{b}}$ & $0.32 \pm 0.07^{\mathrm{a}}$ & $0.19 \pm 0.07^{\mathrm{ab}}$ & * \\
\hline & SE & $0.19 \pm 0.06$ & $0.07 \pm 0.08$ & $0.12 \pm 0.07$ & \\
\hline \multirow[t]{2}{*}{$\mathrm{C} 18: 3 \mathrm{~N} 3$} & LTL & $0.15 \pm 0.06$ & $0.29 \pm 0.07$ & $0.00 \pm 0.07$ & \\
\hline & SE & $0.26 \pm 0.06^{\mathrm{a}}$ & $0.31 \pm 0.08^{\mathrm{a}}$ & $0.10 \pm 0.07^{\mathrm{b}}$ & $*$ \\
\hline \multirow[t]{2}{*}{$\mathrm{C} 20: 2$} & LTL & $0.22 \pm 0.04$ & $0.33 \pm 0.05$ & $0.23 \pm 0.05$ & \\
\hline & SE & $0.13 \pm 0.04$ & $0.16 \pm 0.05$ & $0.23 \pm 0.05$ & \\
\hline \multirow[t]{2}{*}{$\mathrm{C} 20: 3 \mathrm{n} 6$} & LTL & $0.75 \pm 0.25$ & $0.72 \pm 0.30$ & $0.32 \pm 0.28$ & \\
\hline & SE & $0.49 \pm 0.25$ & $0.47 \pm 0.32$ & $0.47 \pm 0.30$ & \\
\hline \multirow[t]{2}{*}{$\mathrm{C} 22: \ln 9$} & LTL & $0.14 \pm 0.16^{b}$ & $0.33 \pm 0.19^{\mathrm{ab}}$ & $0.59 \pm 0.18^{\mathrm{a}}$ & * \\
\hline & SE & $0.63 \pm 0.16$ & $0.33 \pm 0.20$ & $0.45 \pm 0.19$ & \\
\hline \multirow[t]{2}{*}{$\mathrm{C} 20: 3 \mathrm{n} 3$} & LTL & $0.49 \pm 0.19$ & $0.15 \pm 0.23$ & $0.23 \pm 0.21$ & \\
\hline & SE & $0.32 \pm 0.19$ & $0.43 \pm 0.25$ & $0.44 \pm 0.23$ & \\
\hline \multirow{2}{*}{$\mathrm{C} 20: 4 \mathrm{n} 6$} & LTL & $0.28 \pm 0.23$ & $0.04 \pm 0.28$ & $0.38 \pm 0.26$ & \\
\hline & SE & $0.73 \pm 0.23$ & $0.21 \pm 0.30$ & $0.73 \pm 0.28$ & \\
\hline \multirow[t]{2}{*}{ C22:2 } & LTL & $0.10 \pm 0.05^{\mathrm{ab}}$ & $0.23 \pm 0.06^{\mathrm{a}}$ & $0.07 \pm 0.06^{\mathrm{b}}$ & $*$ \\
\hline & SE & $0.13 \pm 0.05^{\mathrm{ab}}$ & $0.26 \pm 0.07^{\mathrm{a}}$ & $0.10 \pm 0.06^{\mathrm{b}}$ & $*$ \\
\hline \multirow[t]{2}{*}{$\mathrm{C} 20: 5 \mathrm{n} 3$} & LTL & $0.54 \pm 0.14$ & $0.49 \pm 0.17$ & $0.28 \pm 0.16$ & \\
\hline & $\mathrm{SE}$ & $0.38 \pm 0.14$ & $0.27 \pm 0.18$ & $0.38 \pm 0.17$ & \\
\hline \multirow[t]{2}{*}{$\mathrm{C} 24: 1$} & LTL & $0.80 \pm 0.15^{\mathrm{a}}$ & $0.75 \pm 0.18^{\mathrm{ab}}$ & $0.39 \pm 0.17^{b}$ & $*$ \\
\hline & SE & $0.56 \pm 0.15$ & $0.34 \pm 0.20$ & $0.17 \pm 0.18$ & \\
\hline \multirow[t]{2}{*}{ C22:6n3 } & LTL & $0.52 \pm 0.14$ & $0.68 \pm 0.16$ & $0.60 \pm 0.15$ & \\
\hline & SE & $0.47 \pm 0.14$ & $0.39 \pm 0.17$ & $0.58 \pm 0.16$ & \\
\hline \multirow[t]{2}{*}{ UFA } & LTL & $50.50 \pm 1.34^{\mathrm{a}}$ & $48.19 \pm 1.60^{\mathrm{ab}}$ & $46.03 \pm 1.50^{\mathrm{b}}$ & * \\
\hline & $\mathrm{SE}$ & $53.35 \pm 1.34$ & $51.95 \pm 1.73$ & $50.24 \pm 1.60$ & \\
\hline \multirow[t]{2}{*}{ MUFA } & LTL & $41.50 \pm 1.49$ & $39.31 \pm 1.78$ & $38.05 \pm 1.67$ & \\
\hline & $\mathrm{SE}$ & $39.48 \pm 1.49$ & $40.67 \pm 1.92$ & $38.14 \pm 1.78$ & \\
\hline \multirow[t]{2}{*}{ PUFA } & LTL & $9.00 \pm 1.17$ & $8.88 \pm 1.40$ & $7.99 \pm 1.31$ & \\
\hline & SE & $13.86 \pm 1.17$ & $11.18 \pm 1.50$ & $12.00 \pm 1.39$ & \\
\hline \multirow[t]{2}{*}{ N6 } & LTL & $7.18 \pm 1.09$ & $6.81 \pm 1.30$ & $6.28 \pm 1.22$ & \\
\hline & SE & $12.18 \pm 1.09$ & $9.39 \pm 1.40$ & $10.17 \pm 1.29$ & \\
\hline \multirow[t]{2}{*}{ N3 } & LTL & $1.71 \pm 0.26$ & $1.61 \pm 0.31$ & $1.26 \pm 0.29$ & \\
\hline & $\mathrm{SE}$ & $1.43 \pm 0.26$ & $1.37 \pm 0.33$ & $1.85 \pm 0.30$ & \\
\hline
\end{tabular}

${ }^{a, b}$ Values in the same line with different capital letter superscripts mean samples have significant difference. ${ }^{*} \mathrm{p}<0.1 ;{ }^{* *} \mathrm{p}<0.05$.

AS, Angus $\times$ Chinese Simmental; WS, Wagyu $\times$ Chinese; CS, Chinese Simmental; LTL, longissimus thoracis et lumborum; SE, semitendinosus muscles; UFA, unsaturated fatty acid; MUFA, monounsaturated fatty acids. 
demonstrated that $\mathrm{C} 18: 1 \mathrm{n} 9 \mathrm{c}$ could reduce LDL cholesterol to prevent arteriosclerosis without decreasing the level of the beneficial HDL cholesterol in humans (Enser et al., 1998). C18:1n9 is suggested to be positively associated with the softness of fat (Vahmani et al., 2015). Also, higher proportion of C18:1n9c could improve the sensory quality of beef (Van Ba et al., 2013). Significant breed difference was detected in the value of C18:1n9c. AS expressed significantly higher $(p<0.05)$ proportion of $\mathrm{C} 18: \ln 9 \mathrm{c}$ compared with CS breed, which might be an advantage for AS breed.

In addition, breed difference tended to exerted in several UFAs. For SE muscle, AS tended $(\mathrm{p}<0.10)$ to have higher myristoleic acid (C14:1) compared with WS, and higher linolenic acid (C18:3n3) compared with CS; while WS tended $(\mathrm{p}<0.10)$ to have higher cis-10-pentadecenoic acid (C15:1) than AS and CS, and higher cis-13,16-docosadienoic acid (C22:2) than AS. C18:3n3 is one of the polyunsaturated fatty acid (PUFA) considered good for human health (Widmann et al., 2011). Here, the tendency of higher $\mathrm{C} 18: 3 \mathrm{n} 3$ in AS breed was in consistent with some previous investigations which reported higher $(\mathrm{p}<0.01) \mathrm{C} 18: 3 \mathrm{n} 3$ content in Aberdeen Angus relative to Charolais, Simmental, and Hereford bulls (Bures et al., 2006; Itoh et al., 1999). For LTL muscle, $\mathrm{C} 16: 1$ and $\mathrm{C} 22: 1 \mathrm{n} 9$ had a tendency $(\mathrm{p}<0.10)$ to be higher in CS than in AS breed. WS tended $(\mathrm{p}<0.10)$ to be higher in $\mathrm{C} 20: 1$ and $\mathrm{C} 22: 2$ compared with AS. While $\mathrm{C} 24: 1$ and total UFA tended $(\mathrm{p}<0.10)$ to be higher in AS than in CS breed. The tendency of higher total UFA proportion in AS might be attributed to the significantly higher percentage of $\mathrm{C} 18: \ln 9 \mathrm{c}$ in AS compared with CS. UFA have a certain protective effect against the cardiovascular disease, and could delay the occurrence of atherosclerosis disease (Nogi et al., 2011). Thus, ongoing efforts have been put into improving the UFA profile in beef to provide a more desirable beef product for consumers' need. These data suggested that the content of $\mathrm{C} 18: 1 \mathrm{n} 9 \mathrm{c}, \mathrm{C} 18: 3 \mathrm{n} 3$, and total UFA in CS could be enhanced by cross-breeding with Angus cattle due to positive heterosis, and Angus $\times$ Simmental breed might be a better choice both for flavor and health.

To evaluate the nutritional properties of intramuscular fat, the ratio of PUFA/SFA, n-6/n-3, SFA/UFA, and MUFA/PUFA was determined (Table 5). Breed difference was observed in the ratio of SFA/UFA and MUFA/PUFA in LTL muscle. AS presented significantly lower $(\mathrm{p}<0.05)$ SFA/UFA ratio compared with CS. The ratio of MUFA/PUFA was significantly lower $(p<0.05)$ in WS than in CS. High ratio of SFA/UFA is believed to have strong correlation with many pathological states in humans, such as increased risks of vascular and coronary diseases (Calder and Deckelbaum, 2003). Thus, lower ratio SFA is

Table 5. Least squares means and standard errors for fatty acids ratio of Angus $\times$ CS, WagyuxChinese, and CS in longissimus dorsi and semitendinosus muscles

\begin{tabular}{|c|c|c|c|c|c|}
\hline Fatty acid ratios & Tissue & AS & WS & $\mathrm{CS}$ & p-values \\
\hline \multirow[t]{2}{*}{$\mathrm{P} / \mathrm{S}$} & LTL & $0.17 \pm 0.02$ & $0.16 \pm 0.03$ & $0.14 \pm 0.03$ & \\
\hline & $\mathrm{SE}$ & $0.29 \pm 0.02$ & $0.23 \pm 0.03$ & $0.23 \pm 0.03$ & \\
\hline \multirow[t]{2}{*}{ N6/N3 } & LTL & $5.34 \pm 2.53$ & $5.42 \pm 3.02$ & $5.81 \pm 2.82$ & \\
\hline & $\mathrm{SE}$ & $9.72 \pm 2.53$ & $8.56 \pm 3.25$ & $12.79 \pm 3.01$ & \\
\hline \multirow[t]{2}{*}{ SFA/UFA } & LTL & $1.04 \pm 0.06^{\mathrm{b}}$ & $1.14 \pm 0.08^{\mathrm{ab}}$ & $1.26 \pm 0.07^{\mathrm{a}}$ & ** \\
\hline & SE & $0.94 \pm 0.06$ & $0.98 \pm 0.08$ & $1.04 \pm 0.07$ & \\
\hline \multirow[t]{2}{*}{ MUFA/PUFA } & LTL & $5.49 \pm 0.92^{\mathrm{ab}}$ & $4.80 \pm 1.09^{\mathrm{b}}$ & $8.05 \pm 1.02^{\mathrm{a}}$ & ** \\
\hline & SE & $2.96 \pm 0.92$ & $3.77 \pm 1.18$ & $3.57 \pm 1.09$ & \\
\hline
\end{tabular}

a,b Values in the same line with different capital letter superscripts mean samples have significant difference. *** $\mathrm{p}<0.05$.

AS, Angus $\times$ Chinese Simmental; WS, Wagyu $\times$ Chinese; CS, Chinese Simmental; LTL, longissimus thoracis et lumborum; SE, semitendinosus muscles; SFA, saturated fatty acid; UFA, unsaturated fatty acid; MUFA, monounsaturated fatty acids. 
preferable (Piot et al., 1998). It is suggested that to minimize the intake of SFA and enhance the intake of PUFA can minimize the risk of cardiovascular diseases (Hoffman and Wiklund, 2006; Wood et al., 2003). Thus, many have focused on producing meat with a higher ratio of PUFA/SFA (Wood et al., 2004). The PUFA/SFA ratio in this study showed mean values ranged from 0.14 to 0.29 , which were lower than the recommendations (0.45) of the British Department of Health (1994) (Department of Health, 1994). However, beef typically has a ratio of 0.1 (Enser, 2000), and similar values were found for this ratio in other purebred and crossbred beef (Bermingham et al., 2018; Bhuiyan et al., 2017; Domingo et al., 2015; Piao et al., 2019). Significant breed difference did not express in the PUFA/SFA ratio. Yet, AS had a numerically highest value of 0.29 in SE muscle, which might be an advantage.

An excessive amount of n-3 PUFAs and a high n-6/n-3 ratio implicate in the promotion of many diseases (Przybylski and Hopkins, 2015). PUFA from the $n-6$ series are involved in the synthesis of eicosanoids biologically active in very small quantities and with properties much more inflammatory than eicosanoids from the n-3 series (Simopoulos, 2002). Thus, nutritional guideline recommends to minimize the intake of $n-6$ fatty acids relative to $n-3$ fatty acids (Department of Health, 1994). The obtained n-6/n-3 ratio in this study ranged from 5.34 to 12.79 , which was all exceed nutritional recommendations of 0.45 (Department of Health, 1994). The results obtained in other studies assessing Galician Blond (Bispo et al., 2010). Belgian Blue and Limousin (Cuvelier et al., 2006), and crossbreed of Holstein with Gallega, Limousine, and Belgian Blue (Domingo et al., 2015), showed similar behavior and were higher than those showed in this work. Significant breed difference did not express in the n-6/n-3 ratio. Yet, AS had a numerically lowest value of 5.34 in LTL muscle. Thus, AS breed might have slight edge than WS and CS in the context of human health.

\section{Meat quality}

Results related to meat quality were presented in Table 6 . The $\mathrm{pH}$ values were measured $72 \mathrm{~h}$ post mortem. In LTL muscle, the $\mathrm{pH}$ value was significantly higher $(\mathrm{p}<0.05)$ in AS and WS compared with CS. Both AS and WS breeds had a $\mathrm{pH}$ value over 6, which exceeded the normal range for beef (5.4-5.8) (Mueller et al., 2019; Zheng et al., 2018). Preslaughter conditions, stress, muscle physiology, and breed might be associated with these atypical pHs (Oliveira et al., 2012). The $\mathrm{pH}$ values in SE muscle ranged between 5.65 and 5.86, which was within normal range. Significant breed difference also expressed in the meat color profile. WS showed significantly higher $(\mathrm{p}<0.05) \mathrm{CIE} \mathrm{L}^{*}$ (lightness) compared with CS, higher $(\mathrm{p}<0.05)$ CIE $\mathrm{a}^{*}$ (redness) and CIE $\mathrm{b}^{*}$ (yellowness) compared with AS and CS in LTL muscle. While AS had significantly higher $(\mathrm{p}<0.05)$ CIE $\mathrm{a}^{*}$ (redness) and CIE $\mathrm{b}^{*}$ (yellowness) compared with CS in SE muscle. Meat color is a dominant factor that affects consumer acceptance, purchasing decisions, and satisfaction, since meat color is used as an indicator of freshness and wholesomeness (Lawrie, 2006; Mancini and Hunt, 2005). Results from this study indicated that crossbreeds of AS and WS could produce visually more appealing meat with lighter, more yellow-red and a more saturated colour.

Water holding capacity is known as the ability of muscle to bind water under a given set of conditions, which is related to sensory characteristics of meat regarding flavor and juiciness, and even economic efficiency (Lawrie, 2006). Significant breed differences were exhibited for water holding capacity parameters. Cooking losses in this study remained between $11.23 \%$ and 34.87\%, within the normal range for beef (Muchenje et al., 2009). AS and WS exhibited significantly lower $(\mathrm{p}<0.05)$ retort cooking loss, pressing loss, and moist cooking loss compared with CS in LTL muscle. WS showed significantly lower $(\mathrm{p}<0.05)$ pressing loss compared with $\mathrm{CS}$, and AS had significantly lower $(\mathrm{p}<0.05)$ moist cooking loss compared with CS in SE muscle. Cooking loss and pressing loss are both negatively associated with the water holding capacity and are used as indicators of meat juiciness (Cao et al., 2019). There results suggested that AS and WS crossbreeds 
Table 6. Least squares means and standard errors for meat quality of Angus $\times$ CS, WagyuxChinese, and CS in longissimus dorsi and semitendinosus muscles

\begin{tabular}{|c|c|c|c|c|c|}
\hline Meat quality traits & Tissue & AS & WS & $\mathrm{CS}$ & p-values \\
\hline $\mathrm{pH}$ & SE & $5.65 \pm 0.43$ & $5.86 \pm 0.43$ & $5.79 \pm 0.35$ & \\
\hline \multirow[t]{2}{*}{ CIE L* } & LTL & $49.01 \pm 1.38^{\mathrm{ab}}$ & $49.79 \pm 2.06^{\mathrm{a}}$ & $48.72 \pm 1.51^{\mathrm{b}}$ & $* *$ \\
\hline & SE & $49.30 \pm 1.04$ & $49.24 \pm 1.53$ & $48.81 \pm 1.16$ & \\
\hline CIE a* & $\mathrm{SE}$ & $5.60 \pm 1.77^{\mathrm{a}}$ & $5.46 \pm 1.31^{\mathrm{a}}$ & $4.26 \pm 1.03^{b}$ & ** \\
\hline \multirow[t]{2}{*}{ CIE b* } & LTL & $13.39 \pm 0.55^{\mathrm{b}}$ & $13.94 \pm 0.77^{\mathrm{a}}$ & $12.86 \pm 0.83^{\mathrm{c}}$ & $* *$ \\
\hline & $\mathrm{SE}$ & $12.70 \pm 0.66^{\mathrm{a}}$ & $12.58 \pm 0.69^{\mathrm{ab}}$ & $11.89 \pm 2.20^{\mathrm{b}}$ & $* *$ \\
\hline Retort cooking loss $(\%)$ & LTL & $29.27 \pm 6.21^{\mathrm{b}}$ & $30.15 \pm 6.92^{\mathrm{b}}$ & $34.87 \pm 6.42^{\mathrm{a}}$ & ** \\
\hline Pressing loss $(\%)$ & SE & $12.58 \pm 4.06^{\mathrm{ab}}$ & $11.97 \pm 4.03^{\mathrm{b}}$ & $14.09 \pm 5.39^{\mathrm{a}}$ & $* *$ \\
\hline \multirow[t]{2}{*}{ Moist cooking loss (\%) } & LTL & $13.40 \pm 6.79^{\mathrm{b}}$ & $15.61 \pm 4.37^{\mathrm{b}}$ & $20.32 \pm 7.58^{\mathrm{a}}$ & $* *$ \\
\hline & $\mathrm{SE}$ & $11.23 \pm 3.06^{\mathrm{b}}$ & $12.76 \pm 5.42^{\mathrm{ab}}$ & $16.02 \pm 6.35^{\mathrm{a}}$ & ** \\
\hline \multirow[t]{2}{*}{ Shear force $(\mathrm{kg})$} & LTL & $2.20 \pm 1.03^{b}$ & $2.87 \pm 2.04^{\mathrm{b}}$ & $4.03 \pm 2.02^{\mathrm{a}}$ & $* *$ \\
\hline & SE & $2.97 \pm 1.12^{\mathrm{b}}$ & $3.19 \pm 1.66^{b}$ & $4.46 \pm 2.13^{\mathrm{a}}$ & $* *$ \\
\hline
\end{tabular}

${ }^{\mathrm{a}, \mathrm{b}}$ Values in the same line with different capital letter superscripts mean samples have significant difference. The same as below. ${ }^{*} \mathrm{p}<0.1 ;{ }^{* *} \mathrm{p}<0.05 ;{ }^{* * *} \mathrm{p}<0.01$.

AS, Angus $\times$ Chinese Simmental; WS, Wagyu $\times$ Chinese; CS, Chinese Simmental; LTL, longissimus thoracis et lumborum; SE, semitendinosus muscles.

might improve the water holding capacity and juiciness of LTL and SE muscles.

Tenderness is the most important determinant of meat quality, which can be quantified by the Warner-Bratzler shear force test (Cao et al., 2019; Przybylski and Hopkins, 2015). The mean shear force found in this study ranged from 2.20 to 4.46 $\mathrm{kg} / \mathrm{cm}^{2}$, which was within the limit for the tenderness in beef $\left(4.5 \mathrm{~kg} / \mathrm{cm}^{2}\right)$ (Belew et al., 2003). Besides, significant breed differences were for shear force values. AS and WS had significantly lower $(p<0.05)$ shear force compared with CS in both LTL and SE muscles, and more than a 1.5-fold decrease was observed in the shear force of AS compared with CS. As tenderness increased with a decrease in shear force (Bhuiyan et al., 2017) AS and WS crossbreeds might produce more tender meat, with AS has a slight edge over WS.

\section{Conclusion}

Collectively, breed difference exists in fatty acid profile and meat quality from beefs of different muscles, indicating that it may be possible to crossbred Angus or Wagyu with CS to enhance the quality of beef. For meat quality, both WS and AS crossbreed improved meat color, water holding capacity, and tenderness of CS. Considering fatty acid profile, crossbreed of AS maybe a preferable choice with significantly less palmitic acid (C16:0), more oleic acid (C18:1n9c), and a tendency to lower total SFA and improve total UFA, to provide consumers a healthier beef product with more juiciness and tenderness. However, many factors, such as slaughter weight, gender, age, feedstock ect., can affect the fatty acid composition and meat quality in tissues, meaning that future research is needed to evaluate the effect of these factors have on fatty acids and meat 
quality in CS crossbred to verify our results.

\section{Conflicts of Interest}

The authors declare no potential conflicts of interest.

\section{Acknowledgements}

The research team would like to express their deep appreciation to the staff at Gansu Jinyuan Animal Husbandry, Ltd. for the use of their facilities and their assistance in conducting the study. The authors also would like to thank the undergraduate and graduate students for helping in this research.

This research is supported by Major Science and Technology Special Program of Gansu Province: Research and Demonstration of High Efficiency Eco-nutrition Technology System for Beef Cattle (No. 17ZD2NC020), Ministry of Agriculture Public Welfare Industry (Agriculture) Scientific Research Project: Research and Demonstration of Feeding and Utilization Technology of Crop Straw in North China (No. 201503134), and Research and Demonstration on Key Technologies of Straw Feeding Chemical Vapor Blasting Wall Fermentation in Gansu Agriculture and Animal Husbandry Department (2018 Special Project). Special project of modern agriculture (herbivore and livestock) industrial technology system in Gansu Province (No. GARS-CSX-1).

\section{Author Contributions}

Conceptualization: Liu T, Lei ZM. Data curation: Wu JP, Gong XY. Formal analysis: Zhang M, Cheng SR. Methodology: Liu T, Gong XY, Wang JF. Software: Wu JP, Cheng SR, Zhang M. Validation: Liu T, Lei ZM. Investigation: Liang Y, Wang JF. Writing - original draft: Liu T, Lei ZM. Writing - review \& editing: Liu T, Wu JP, Lei ZM, Zhang M, Gong XY, Cheng SR, Liang Y. Wang JF.

\section{Ethics Approval}

This study was approved by Gansu Agricultural University Animal Care and Use Committee (approved No. 2012-2-159).

\section{References}

Belew JB, Brooks JC, Mckenna DR, Savell JW. 2003. Warner-Bratzler shear evaluations of 40 bovine muscles. Meat Sci 64:507-512.

Bermingham EN, Reis MG, Subbaraj AK, Cameron-Smith D, Fraser K, Jonker A, Craigie CR. 2018. Distribution of fatty acids and phospholipids in different table cuts and co-products from new zealand pasture-fed Wagyu-dairy cross beef cattle. Meat Sci 140:26-37.

Bhuiyan MSA, Lee DH, Kim HJ, Lee SH, Cho SH, Yang BS, Kim SD, Lee SH. 2017. Estimates of genetic parameters for fatty acid compositions in the longissimus dorsi muscle of hanwoo cattle. Animal 12:675-683.

Bispo E, Moreno T, Thomas A, Durand D, Monserrat L, Gonzalez L, Bauchart D. 2010. Effects of weaning and finishing 
feeding treatment on fatty acids, especially cis and trans C18:1 isomers, in the longissimus thoracis muscle of Galician Blond calves. Animal 5:802-812.

Blanco M, Villalba D, Ripoll G, Sauerwein H, Casasus I. 2009. Effects of early weaning and breed on calf performance and carcass and meat quality in autumn-born bull calves. Livest Sci 120:103-115.

Briggs MA, Petersen KS, Kris-Etherton PM. 2017. Saturated fatty acids and cardiovascular disease: Replacements for saturated fat to reduce cardiovascular risk. Healthcare 5:29.

Bures D, Barton L, Zahradkova R, Teslik V, Krejcova M. 2006. Chemical composition, sensory characteristics, and fatty acid profile of muscle from Aberdeen Angus, Charolais, Simmental, and Hereford bulls. Czech J Anim Sci 51:279-284.

Calder PC, Deckelbaum RJ. 2003. Fat as a physiological regulator: The news gets better. Curr Opin Clin Nutr Metab Care 6:127-131.

Calkins CR, Hodgen JM. 2007. A fresh look at meat flavor. Meat Sci 77:63-80.

Cao XK, Cheng J, Huang YZ, Wang XG, Ma YL, Peng SJ, Chaogetu BR, Zhuoma ZX, Chen H. 2019. Growth performance and meat quality evaluations in three-way cross cattle developed for the Tibetan Plateau and their molecular understanding by integrative omics analysis. J Agric Food Chem 67:541-550.

Coleman LW, Hickson RE, Schreurs NM, Martin NP, Kenyon PR, Lopez-Villalobos N, Morris ST. 2016. Carcass characteristics and meat quality of hereford sired steers born to beef-cross-dairy and Angus breeding cows. Meat Sci 121:403-408.

Cuvelier C, Clinquart A, Hocquette JF, Cabaraux JF, Dufrasne I, Istasse L, Hornick JL. 2006. Comparison of composition and quality traits of meat from young finishing bulls from Belgian Blue, Limousin and Aberdeen Angus breeds. Meat Sci 74:522-531.

De Smet S, Raes K, Demeyer D. 2004. Meat fatty acid composition as affected by fatness and genetic factors: A review. Anim Res 53:81-98.

Department of Health. 1994. Nutritional aspects of cardiovascular disease. Report on health and social subjects, no. 46. Her Majesty's Stationery Office, London, UK. p 186.

Domingo G, Iglesias A, Monserrat L, Sanchez L, Cantalapiedra J, Lorenzo JM. 2015. Effect of crossbreeding with Limousine, Rubia Gallega and Belgium Blue on meat quality and fatty acid profile of Holstein calves. Anim Sci J 86:913-921.

Enser M. 2000. Producing meat for healthy eating. Proceedings of Forty Sixth International Congress Meat Science \& Technology, Buenos Aires, Argentina. pp 124-129.

Enser M, Hallett KG, Hewett B, Fursey GAJ, Wood JD, Harrington G. 1998. Fatty acid content and composition of UK beef and lamb muscle in relation to production system and implications for human nutrition. Meat Sci 49:329-341.

Erkkila A, De Mello VDF, Riserus U, Laaksonen DE. 2008. Dietary fatty acids and cardiovascular disease: An epidemiological approach. Prog Lipid Res 47:172-187.

Garmyn AJ, Hilton GG, Mateescu RG, Morgan JB, Reecy JM, Tait RG, Jr., Beitz DC, Duan Q, Schoonmaker JP, Mayes MS, Drewnoski ME, Liu Q, Vanoverbeke DL. 2011. Estimation of relationships between mineral concentration and fatty acid composition of longissimus muscle and beef palatability traits. J Anim Sci 89:2849-2858.

Hoffman LC, Wiklund E. 2006. Game and venison: Meat for the modern consumer. Meat Sci 74:197-208.

Itoh M, Johnson CB, Cosgrove GP, Muir PD, Purchas RW. 1999. Intramuscular fatty acid composition of neutral and polar lipids for heavy-weight Angus and Simmental steers finished on pasture or grain. J Sci Food Agric 79:821-827.

Kazala EC, Lozeman FJ, Mir PS, Laroche A, Bailey DRC, Weselake RJ. 1999. Relationship of fatty acid composition to 
intramuscular fat content in beef from crossbred Wagyu cattle. J Anim Sci 77:1717-1725.

Lawrie RA. 2006. The eating quality of meat. In Lawrie's meat science. $7^{\text {th }}$ ed. Lawrie RA (ed). Woodhead, Duxford, UK. pp 279-337.

Malau-Aduli AEO, Edriss MA, Siebert BD, Bottema CDK, Pitchford WS. 2000. Breed differences and genetic parameters for melting point, marbling score and fatty acid composition of lot-fed cattle. J Anim Physiol Anim Nutr 83:95-105.

Maltin C, Balcerzak D, Tilley R, Delday M. 2007. Determinants of meat quality: Tenderness. Proc Nutr Soc 62:337-347.

Mancini RA, Hunt MC. 2005. Current research in meat color. Meat Sci 71:100-121.

May SG, Sturdivant CA, Lunt DK, Miller RK, Smith SB. 1993. Comparison of sensory characteristics and fatty acid composition between Wagyu crossbred and Angus steers. Meat Sci 35:289-298.

Mir Z, Paterson LJ, Mir PS. 2000. Fatty acid composition and conjugated linoleic acid content of intramuscular fat in crossbred cattle with and without Wagyu genetics fed a barley-based diet. Can J Anim Sci 80:195-197.

Muchenje V, Dzama K, Chimonyo M, Strydom PE, Hugo A, Raats JG. 2009. Some biochemical aspects pertaining to beef eating quality and consumer health: A review. Food Chem 112:279-289.

Mueller LF, Balieiro JCC, Ferrinho AM, Martins TDS, Da Silva Corte RRP, De Amorim TR, De Jesus Mangini Furlan J, Baldi F, Pereira ASC. 2019. Gender status effect on carcass and meat quality traits of feedlot Angus $\times$ Nellore cattle. Anim Sci J 90:1078-1089.

Nogi T, Honda T, Mukai F, Okagaki T, Oyama K. 2011. Heritabilities and genetic correlations of fatty acid compositions in longissimus muscle lipid with carcass traits in Japanese Black cattle. J Anim Sci 89:615-621.

Nuernberg K, Dannenberger D, Nuernberg G, Ender K, Voigt J, Scollan ND, Wood JD, Nute GR, Richardson RI. 2005. Effect of a grass-based and a concentrate feeding system on meat quality characteristics and fatty acid composition of longissimus muscle in different cattle breeds. Livest Prod Sci 94:137-147.

O'fallon JV, Busboom JR, Nelson ML, Gaskins CT. 2007. A direct method for fatty acid methyl ester synthesis: Application to wet meat tissues, oils, and feedstuffs. J Anim Sci 85:1511-1521.

Oliveira EA, Sampaio AAM, Henrique W, Pivaro TM, Rosa BL, Fernandes ARM, Andrade AT. 2012. Quality traits and lipid composition of meat from nellore young bulls fed with different oils either protected or unprotected from rumen degradation. Meat Sci 90:28-35.

Papaleo Mazzucco J, Goszczynski DE, Ripoli MV, Melucci LM, Pardo AM, Colatto E, Rogberg-Muñoz A, Mezzadra CA, Depetris GJ, Giovambattista G, Villarreal EL. 2016. Growth, carcass and meat quality traits in beef from Angus, Hereford and cross-breed grazing steers, and their association with snps in genes related to fat deposition metabolism. Meat Sci 114:121-129.

Piao MY, Lee HJ, Yong HI, Beak SH, Kim HJ, Jo C, Wiryawan KG, Baik M. 2019. Comparison of reducing sugar content, sensory traits, and fatty acids and volatile compound profiles of the longissimus thoracis among Korean cattle, Holsteins, and Angus steers. Asian-Australas J Anim Sci 32:126-136.

Pighin D, Pazos A, Chamorro V, Paschetta F, Cunzolo S, Godoy F, Messina V, Pordomingo A, Grigioni G. 2016. A contribution of beef to human health: A review of the role of the animal production systems. Sci World J 2016:8681491.

Piot C, Veerkamp JH, Bauchart D, Hocquette JF. 1998. Contribution of mitochondria and peroxisomes to palmitate oxidation in rat and bovine tissues. Comp Biochem Physiol Part B BiochemMol Biol 121:185-194.

Przybylski W, Hopkins D. 2015. Meat quality: Genetic and environmental factors. CRC Press, Boca Raton, FL, USA. p 472. Purchas RW, Knight TW, Busboom JR. 2005. The effect of production system and age on concentrations of fatty acids in 
intramuscular fat of the longissimus and triceps brachii muscles of Angus-cross heifers. Meat Sci 70:597-603.

Resurreccion AVA. 2004. Sensory aspects of consumer choices for meat and meat products. Meat Sci 66:11-20.

Simopoulos AP. 2002. The importance of the ratio of omega-6/omega-3 essential fatty acids. Biomed Pharmacother 56:365379.

Vahmani P, Mapiye C, Prieto N, Rolland DC, Mcallister TA, Aalhus JL, Dugan MER. 2015. The scope for manipulating the polyunsaturated fatty acid content of beef: A review. J Anim Sci Biotechnol 6:29.

Van Ba H, Amna T, Hwang I. 2013. Significant influence of particular unsaturated fatty acids and $\mathrm{pH}$ on the volatile compounds in meat-like model systems. Meat Sci 94:480-488.

Webb EC, O'neill HA. 2008. The animal fat paradox and meat quality. Meat Sci 80:28-36.

Widmann P, Nuernberg K, Kuehn C, Weikard R. 2011. Association of an ACSL1 gene variant with polyunsaturated fatty acids in bovine skeletal muscle. BMC Genet 12:96.

Wood JD, Enser M, Fisher AV, Nute GR, Sheard PR, Richardson RI, Hughes SI, Whittington FM. 2008. Fat deposition, fatty acid composition and meat quality: A review. Meat Sci 78:343-358.

Wood JD, Richardson RI, Nute GR, Fisher AV, Campo MM, Kasapidou E, Sheard PR, Enser M. 2003. Effects of fatty acids on meat quality: A review. Meat Sci 66:21-32.

Wood JD, Richardson RI, Nute GR, Fisher AV, Campo MM, Kasapidou E, Sheard PR, Enser M. 2004. Effects of fatty acids on meat quality: A review. Meat Sci 66:21-32.

Zhang YH, Yan P, Liang CN, Zeng YF. 2009. Composition analysis on intermuscular fatty acid of Qinghai Datong yak. Agric Sci Technol 10:145-148.

Zheng Y, Wang S, Yan P. 2018. The meat quality, muscle fiber characteristics and fatty acid profile in Jinjiang and $F_{1}$ Simmental $\times$ Jinjiang Yellow cattle. Asian-Australas J Anim Sci 31:301-308. 